\title{
Erik Allardt
}

\section{Perspektiv och \\ perspektivförskjutningar inom nordisk sociologi}

1900-talet är sociologins århundrade. Sociologins och sociologernas synsätt har dock inte varit det samma under hela seklet. I själva verket har 1900-talets sociologi utmärkts av mycket stora perspektivförskjutningar. 
Stora paradigmer och perspektivförskjutningar i 1900-talets sociologi

De stora växlingarna i den finländske etnosociologen och moralfilosofen Edward Westermarcks popularitet ger en förbluffande god utgångspunkt vid en beskrivning av perspektivförändringarna i 1900-talets sociologi. Westermarck (1862-1939) var under början av 1900talet en ledande sociologisk teoretiker, men glömdes sedan mer eller mindre bort för att under 1900-talets två sista decennier på nytt få en viss grad av aktualitet.

Edward Westermarcks första stora arbete behandlade äktenskapets historia och ursprung. Den uttryckte en evolutionisk hållning med Charles Darwin som förebild och en tro på att sociologin skall kunna erbjuda lika grundläggande insikter om de sociala institutionernas ursprung som den darwinistiska evolutionismen om arternas uppkomst.

När Westermarcks The History of Human Marriage utkom år 1891 på MacMillans förlag väckte den genast sensation, översattes till sju språk och blev ett diskussionsämne inte bara i lärda, utan också i litterärt kulturella kretsar. Av teoretiskt ännu större betydelse var hans andra stora arbete The Origin and Development of the Moral Ideas, som utkom i två omfattande band på MacMillans förlag 1906-1908. När Westermarcks och hans elever i sina arbetens rubriker talade om olika sociala institutioners ursprung, the origin, avsåg de dock inte det historiskt kronologiska ursprunget utan den psykologiska och biologiska bakgrunden till institutionernas existens. Westermarcks strävan var att påvisa universella kulturformer, biocultural universals, som var nödvändiga för människors överlevnad.

Westermarcks på Darwin och evolutionismen baserade teorier föll emellertid ganska snart i glömska. Det som sakna- des i Westermarcks tankegångar var att han aldrig behandlade samhällen, inte ens byar och stammar som sociala helheter. Han samlade material från hela världen, men hans sikte var inriktat på individer, ibland också inom djurvärlden, som strävade att överleva i sin miljö. För sina försummelser att beakta sociala enheter kritiserades hans två stora arbeten av bl a Émile Durkheim (1895, 602-623: 1907, 283-295) i två utförliga recensioner.

Det blev också sociologer som Durkheim och socialantropologer som Westermarcks efterträdare vid London School of Economics, Bronislaw Malinowski, som kom att definiera tonvikten inom sociologin under stora delar av 1900-talet. Det blev helt centralt att beskriva samhällen, byar, regioner och grupper som helheter med en någorlunda enhetlig både kultur, normativ värdemiljö och social struktur. Tendensen förstärktes efter andra världskriget då det blev viktigt att analysera sociala förutsättningar för demokrati och välstånd. För den sortens sociologi hade Westermarck ingenting att ge. Hans arbetens position i Finland under den tiden är ganska symptomatisk. Hans hyllades som en av Finlands stora vetenskapsmän och sociologsamfundet i Finland döptes till och heter The Westermarck Society. Samtidigt fanns det ingen bland de finländska sociologerna i efterkrigsgenerationen som stimulerades av eller tillämpade hans tankar. Medan sociologin under 1900-talets första decennium starkt påverkades av Charles Darwin och evolutionismen, blev i synnerhet decennierna efter andra världskriget en period av koncentration på samhälleliga och sociala företeelser såsom solidaritet, social struktur, klasskiktning och socio-kulturella helheter.

Westermarcks position under slutet av 1900-talet är av ett symptomatiskt intresse. Hans tankegångar är inte ge- 
nerellt diskuterade och tillämpade, men de har dock på nytt blivit uppmärksammade. Det finns ett nytt intresse för biologiska perspektiv på samhällsformerna. Westermarcks tankegångar upplever en renässans, kanske inte så mycket bland sociologer som bland en tvärvetenskaplig grupp av biologer, psykologer, antropologer och samhällsvetare med intresse för att analysera strategier för överlevnaden av mänsklig gemenskap. En av dem, den svenske psykiatern Nils Uddenberg, betonar i sin bok Arvsdygden. Biologisk utveckling och mänsklig gemenskap $(1998,184,200)$ hur Westermarck i den mänskliga naturen särskilt sökte universalier för vår överlevnad.

Hur som helst, sociologien befinner sig nu vid millennium-skiftet i ett annat predikament än under största delen av det gångna 1900-talet. Westermarcks renässans är ett uttryck för förändringen, men man kan troligen beskriva den i allmännare termer än att säga att det finns ett nytt intresse för den biologiska bakgrunden. Göran Therborn betonade i ett seminarieföredrag, publicerat i Dansk Sociologi $(1999,22-27)$ hur 1900-talets sociologi sökte regelbundna mönster i social struktur, normer, värderingar och sociala funktioner i avsikt att åstadkomma utveckling och framsteg, men att det nu håller på att uppstå en helt annorlunda social kosmologi. Den betonar strategi, osäkerhet och förmåga att anpassa sig till mycket olika typer av förändringar. I Therborns från engelskan översatta formulering: „den fremherskende socialkosmologi ved dette århundredskifte er meget forskellig fra den, der har vaeret dominerende i sociologiens förste århundrede. Strategi og kontingens har erstattet udvikling og fremskridt, struktur i betydningen funktionel orden og modsaettningsfyldte strukturer og frigörelse".

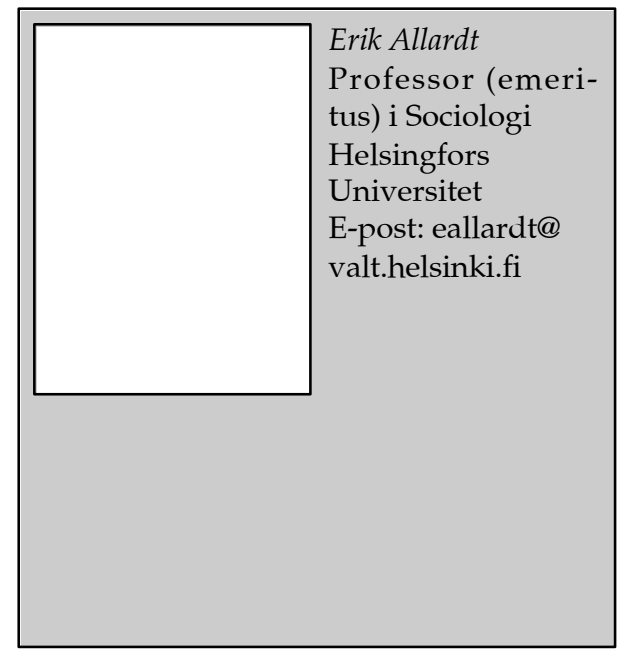

Det förefaller fruktbart att indela sociologins stora faser under 1900-talet i tre perioder:

- en evolutionistiskt orienterad sociologi fram till första världskriget,

- en struktur- och funktionsanalytiskt orienterad och samhällstillvänd sociologi, som i stort sett varit dominerande under 1900-talet, men som hade sin största och mest fruktbara dominans under 1950- och 1960-talen, och

- en nyorientering under 1900-talets sista decennier mot en sociologi, som söker strategier för överlevnad i sociala förhållanden med risker, osäkerhet och ombytlighet.

\section{Den biologiskt determinerade individen}

Trots att den evolutionistiska synen på människan och samhället förlorade sin dominans inom sociologin redan före det första världskriget, utmärktes människokunskapen i de nordiska länderna fram till slutet av 1940-talet av en utpräglat biologisk människosyn. Den stöddes och omfattades av Nordens ledande filosofer 
såsom Eino Kaila i Finland och Jörgen Jörgensen i Danmark. Jörgensens inflytelserika och omfattande lärobok på nästan 700 sidor Psykologi paa biologisk grundlag utkom 1941. Jörgensen ser psykologin som en del av biologin och han hänför också sociala företeelser till den del av biologin, som han kallar ekologi och som bl a innehåller "laeren om forholdet mellem organismerna og deres levende omgivelser" (s. 19). Jörgensens bok innehåller skarpsinniga analyser av människokunskapens begrepp och tankegångar, men hans exempel gäller alltid individer och hur individer reagerar i sociala situationer. Han tillämpar en distinktion mellan en organisms omgivning och omvärld, där han med „omverden forstaar det (formodede) 'billede', som organismen danner sig af sine omgivelser, dvs de faenomener der foreligger for organismen eller den maade, hvorpaa omgivelserne tager sig ud for organismen". När Jörgensen går att med exempel analysera organismens omvärld, dvs dess bild av sin omgivning, behandlar han främst bier, korsedderkopper, blaeksprutte och hönsene (ss. 183-188).

\section{Den till samhällsliv socialiserade människan}

Den utpräglat biologiska människobild, som inflytelserika filosofer som Jörgen Jörgensen och Eino Kaila representerade och framförde, var mycket dominerande fram till åren efter det andra världskriget. Då skedde en påtaglig omsvängning till en betoning av hur människan socialiseras och av omgivningen lär sig beteenden. Om man vill dramatisera förändringen och se den i ett storpolitiskt perspektiv, kan man säga att en av det andra världskrigets följder var att den amerikanska armén tog med sig den amerikanska inlärningspsykologin till Västeuropa. Ett ofta inom den efterkrigstida nordiska sociologin och socialpsy- kologin citerat arbete var Millers och Dollards bok om inlärning och imitering. Något slagsordsmässigt kan den sammanfattas i påståendet att människan inte imiterar automatiskt, utan att hon lär sig av omgivningen att imitera (Boalt 1950, 41-45). Det blev centralt att betona social inlärning och hur människan socialiseras att följa samhällets seder. Ett belysande uttryck för förändringen var den samnordiska tidskriften Menneske og miljö. Människa och miljö, med undertiteln Menneskekundskab og menneskebehandling (1946-48), som under en kort, men inflytelserik period utgavs av Nyt Nordisk Forlag i Köpenhamn, Gleerups förlag i Lund, Natur och kultur i Stockholm samt Akademiska bokhandeln i Helsingfors.

Som en sorts parentes är det dock viktigt att tillägga att under året 1939 utkom en betydande systematisk lärobok i Theodor Geigers Sociologi. Grundrids og hovedproblemer. Den representerade varken den tidens starka biologiska förankring och eller den efterkrigstida faiblessen för amerikansk inlärningspsykologi. Den byggde på en omfattande historisk och samhällsvetenskaplig lärdom och representerade en för den tiden ovanlig inriktning på makrosociologi, samhällssystem och kultur samt ,samfundsdannelser" av olika grad såsom små grupper och samhällen. På grund av världskriget distribuerades den i de andra nordiska länderna först efter 1945 och spelade otvivelaktigt då en roll i alla nordiska länder vid avgränsningen av sociologins objekt och uppgifter.

En särskilt stark betoning av socialisationsprocesser och människan som en produkt av sin symbolmiljö fanns i Torgny Segerstedts sociologi, the Uppsala School of Sociology (Segerstedt 1955, 85119). Segerstedt (1944) betonade ordens makt och hur människor genom sociala normer, som han definierade som verbala 
uttryck med en imperativ funktion, påverkar och dirigerar varandra.

Segerstedt hade många betydande elever, som utan att i detalj följa sin lärare, utarbetade och fullföljde hans intentioner att förklara människors sociala beteende med utgångspunkt i deras symbol- och språkmiljö. Hans internationellt mest kände och länge i USA verksamme elev Hans Zetterberg betonade i teoretiskt skarpsinniga analyser social motivation och hur människan bygger upp och bevarar sin självkänsla så att de motsvarar förväntningarna hos andra aktörer i det sociala systemet. Detta var också den centrala utgångspunkten i Zetterbergs artikel Compliant Actions, som hört till Acta Sociologicas (1957, 179-202) genom tiderna mest uppmärksammade bidrag. Zetterberg var också vid sidan av Talcott Parsons ett av de främsta objekten för den berömda kritik, som Dennis Wrong i artikeln The Oversocialized Concept of Man (1961, 183-193) riktade mot den moderna sociologin. Dennis Wrong hade otvivelaktigt rätt i att 1950- och 1960-talens sociologiska teori ganska ensidigt betonade hur människors handlingsrepertoar huvudsakligen består av att hon försöker motsvara förväntningar samt följa sitt samhälles och sin grupps sociala seder.

Det fanns dock variationer i hur man analyserade och förhöll sig till den sociala miljöns tryck och socialisationsmekanismerna. Särskilt i definitionerna av sociala normer och sociala förväntningar fanns intressanta skillnader mellan svensk och norsk sociologi. När den svenska sociologin i Segerstedts och Zetterbergs anda betonade de språkliga uttryckens och de sociala förväntningarnas normativa kraft, undersökte norska sociologer såsom Vilhelm Aubert och Johan Galtung de sociala normernas sanktioner. De norska sociologernas undersökningar berörde därför på ett centralt sätt avvikare, konflikter och sociala normers dolda och latenta funktioner. Tendensen är explicit uttryckt i titeln på Auberts verk The Hidden Society (1965), på norska Det skjulte samfunn (1969), som kan ståta som ett monument för den tidens lysande norska sociologi. Vilhelm Aubert var inte ensam, men han var en „primus inter pares" i en grupp, som också bestod av bl a Sverre Lysgaard, Nils Christie, Thomas Mathiesen, Odd Ramsöy, Harriet Holter och Yngvar Löchen. Även om de norska sociologerna undersökte avvikare, konflikter och normers latenta funktioner, var deras utgångspunkt inte desto mindre ett någorlunda regelbundet samhälle med en intakt social struktur och enhetliga, om också ofta orättvisa seder och normer, som också definierade avvikelserna.

Tyngdpunkten inom 1950- och 1960talens sociologi låg inte enbart $i$ att analysera och direkt påvisa socialisationsmekanismer, men inom snart sagt alla sociologiska delområden fanns ett besläktat intresse att belysa antingen anpassningen till eller protesten mot en bestämd struktur och värdegemenskap. Inom stora makrociologiska delområden, vid studiet av samhällsklasser och i den politiska sociologin, dominerade ett strukturfunktionalistiskt perspektiv. En ledande och aktiv forskare vid utforskningen av social stratifiering var Kaare Svalastoga. Han utgick explicit från ett strukturfunktionalistiskt antagande att skillnader i rang och status är nödvändiga för att ett samhälle skall kunna fungera, men att differentieringen inte heller får föras längre än nödvändigt för den samhälleliga effektiviteten. „The problem for a society desirous of maximizing its resilience is to balance social rank differentiation against social integration so that rank is no more elaborate than need be for the task, but still sufficient to facilitate the upward flow of talent and the coordination of activity (Svalastoga 1965, 7). 
Inom den politiska sociologin med Stein Rokkan som tongivande forskare dominerade demokratins problem, nationsbildning och analyser av hur periferier mobiliserats att delta i det politiska systemet (Rokkan 1970, 72-144; 181-225). Såsom en av de av Rokkan till den politiska sociologin lockade forskarna jämförde jag industri- och ödemarkskommunismen i Finland för att visa under vilka samhällsförhållanden extremism och strävanden att protestera mot det politiska systemet uppstår (Allardt 1970, 45-63).

Sociologin under en tidsperiod av ca två decennier efter andra världskriget har ofta kallats positivistisk. Det är såtillvida en överdrift att filosofiska deklarationer till förmån för positivismen inte var särskilt vanliga eller centrala. Däremot återspeglade den empiriska sociologiska forskningen i de nordiska länderna en ganska grundmurad uppfattning om att det är möjligt att utföra förhållandevis strikta kausala analyser, att man kan bygga upp sociologiska teorier genom att noggrant definiera begrepp och pröva hypoteser och att det är möjligt att konstruera ett sociologiskt språk med entydiga termer.

\section{Protester, renässanser och orienteringsförsök}

Från och med slutet av 1960-talet började det inom nordisk sociologi såsom $\mathrm{i}$ andra västeuropeiska och nordamerianska länder uppstå protester mot och konkurrerande riktningar med den sociologi, som vuxit sig stark med inriktning på den socialiserade människan, strukturfunktionalistiska analyser av samhället och en positivistiskt orienterad metodologi. Man frågar sig varför många protesters, om inte urspung, så dock tilltagande styrka, kan dateras till andra hälften av 1960-talet. En ganska rimlig förmodan är att det delvis var frågan om mättnads- processer. När sociologin och det sociologiska synsättet i de nordiska länderna under slutet av 1940-talet i snabb fart växte fram, inte bara som ett acceptabelt, utan också som ett populärt akademiskt ämne, representerade sociologin någonting nytt och spännande. Sociologin erbjöd nya idéer, stimuli och lösningar till de problem, som hade uppstått eller genererades under andra världskriget och efterkrigstiden. Sociologin hade en enorm medvind och sociologiska tankegångar förbrukades i snabb takt. Som student, doktorand och novis i en akademisk karriär under 1940-talets andra hälft och 1950-talet upplevde jag hur vissa sociologiska tankegångar, som i början hade varit svåra att förstå och begripa, småningom blev allmängods och miste sin kraft att aktivera unga forskare. Man brukar ibland säga att missnöjet med den etablerade sociologin berodde på att den stått för löften om samhälleliga lösningar som den inte kunde uppfylla. Förmodligen överbetonar förklaringen det rationella i förändringsprocessen. Det var snarare frågan om en omedveten och diffus mättnadprocess.

Hur som helst, mot slutet av 1960talet uppstod en betydande mängd av protester, renässanser av gamla tankegångar och intensiva strävanden att hitta någonting nytt. Man kan kanske grovsortera dem i fyra olika strömningar; (1) antipositivism, (2) kultursociologi med en tonvikt på verklighetens sociala konstruktion, (3) marxismen och (4) feministisk teori.

En av de centrala protesterande riktningarna kan beskrivas såsom antipositivism. Den hade för all del existerat under hela 1900-talet, men den tog ny fart på slutet av 1960-talet. En kritik av positivismmen fanns i alla nordiska länder, men den tog sig ganska olika former. I Norge hade sociologernas kritik av positivismen en stark och fruktbar anknyt- 
ning till sociologins teoretiska traditioner. Uppmärksammade bidrag gjordes av Hans Skjervheim (t ex 1974) och Dag Österberg (t ex 1988). Skjervheim betonade i sina bidrag från 1950-talet och framåt att sociala handlingars intentioner och mening inte $\mathrm{i}$ allmänhet kan uttryckas på ett entydigt sätt i yttre observationer på samma sätt som man inom naturvetenskapen undersöker naturen. I sina metasociologiska analyser beskriver Dag Österberg hur det i det sociala livet existerar både förutsägbara, regelbundna, tingliknande beteenden och helt nya, oförutsägbara handlingar.

I den svenska sociologin anknöts motsatsen positivism kontra antipositivism dels till diskussioner om sociologins metodik, om hårddata eller mjukdata, dels till en debatt om värdeneutraliteten i socialvetenskapen, debatter som främst Johan Asplund startade i tidskriften Sociologisk Forskning (t ex 1968, 245-263). I Finland fick debatten om positivism versus antipositivism en, såsom debatter i Finland ofta gör, stark filosofisk anknytning, uttryckt i bl a Georg Henrik von Wrights bok Explanation and Understanding (1971), med sin analys av hur human- och socialvetenskapens förklaringar inte är kausalt empiriska, utan begreppsliga och följer de praktiska syllogismernas logik.

I Danmark fick antipositivismen en viktig hemort inom kultursociologin. Kultursociologerna inlät sig vanligen inte på filosofiska diskussioner om positivismen, men betonade hur människans sociala relationer definieras av hennes kultur. I boken Slip sociologien lös betonar Jesper Due och Jörgen Sten Madsen särskilt två principer. Den ena är att ett historiskt perspektiv är oundgängligt i sociologin. Den andra fundamentala principen är att de kulturella relationerna är grundläggande i alla sociala företeelser och undersökningar. I principen ingår tanken att människan ständigt skapar sitt sociala liv.

,,...mennesker på en gang er skabt af det sociale liv og selv skaber dette..." (Due and Madsen 1983, 44 och 203).

Kritiken av positivismen var av en „mixed blessing“. Den avslöjade oriktiga antaganden om kausala relationer samt påvisade kulturella föreställningars och språkliga tolkningars centrala roll i de sociala relationerna. Samtidigt togs uppmaningen "slip sociologien lös" alltför bokstavligt och ledde i alla nordiska länder till en uppsjö av undersökningar och avhandlingar baserade på kvalitativa metoder och slappa intuitiva tolkningar utan teoretisk systematik om de sociala mekanismer, som förbinder och förklarar sociala företeelser. Ett synnerligen välkommet arbete var därför den av Peter Hedström och Richard Swedberg redigerade Social Mechanisms. An Analytical Approach to Social Theory (1998) med bidrag av bl a Jon Elster, Gudmund Hernes och Aage Sörensen.

Inom kultursociologin omformades antipositivismen småningom till ett empiriskt forskningsprogram. Den hade olika källor såsom Peter Bergers och Thomas Luckmanns idé om verkligheten som en social konstruktion, Harold Garfinkels etnometodologi och den s k Birmingham-skolan för studiet av underkulturer, men gemensamt för dem alla är antagandet att den sociala verkligheten är en social konstruktion, som i hög grad bygger på den vardagskunskap människor har och det vardagsspråk de använder om samhällsföreteelserna. Synsättet brukar sammanfattas i beteckningen social konstruktivism. De olika varianterna betonar språkets roll på olika sätt, men de brukar alla beskrivas som en följd av en kantring mot det ling- 
vistiska, "the lingvistic turn in sociology". Den lingvistiska kantringen och den sociala konstruktivismen har haft betydande utlöpare i olika länder, av vilka kan nämnas Margaretha Järvinens och Margareta Bertilssons översikt och kritiska analys i Socialkonstruktivisme, Bidrag till en kritisk diskussion (1998) samt Risto Heiskalas (1997) omfattande teoretiska analys i Society as Semiosis. Neostructuralist Theory of Culture and Society. Också sociologins metodologi och metod har analyserats och utvecklats för att bättre kunna svara mot den nya kultursociologins och den sociala konstruktivismens krav såsom skett i Pertti Alasuutaris (1995) metodbok.

Från och med slutet av 1960-talet till slutet av 1970-talet upplevde alla västeuropeiska universitet och kanske särskilt sociologin en återkomst av Karl Marx och en marxistisk renässans

Den marxistiska socialvetenskapen hade olika förgreningar. Den sovjetiska marxismen spelade snart sagt ingen roll för de nordiska marxistiska forskarna. Det fanns särskilt två starka riktningar. Den ena, som kallades kapitallogik på grund av sin utgångspunkt i Karl Marx' Das Kapital, hade sina starka fästen i Tyskland och i Danmark, både vid Köpenhamns och Aarhus universitet (Schanz 1974) samt omfattades också av många marxistiska sociologer i Finland. Den andra, en fransk variant, som ibland kallades strukturell marxism och som såg bl a Louis Althusser som auktoritet, hade i nordisk sociologi stöd i Sverige och Norge samt en speciell fästpunkt vid Lunds universitet. Där presenterades också ett av de främsta och i mitt tycke ett av de få fortfarande levande arbetena från den nordiska sociologiska marxismens guldålder, nämligen Göran Therborns doktorsavhandling Science, Class and Society av år 1974. Therborns arbete frestar en att säga att den nordiska socio- logiska marxismen drev vissa av den dominerande sociologins inriktningar till sin orimliga spets. Sociologer har väl i allmänhet varit engagerade av sitt så att säga sociala samvete och varit angelägna om delta i arbetet på bättre och rättvisare förhållanden. Detta var inte tillräckligt för Therborn, som i början av sin avhandling öppet redogör för sitt engagemang och sin ideologiska anknytning till en radikal arbetarrörelse. Signifikant är hur han betonade att sociologin, för att kunna fullfölja sina egentliga ambitioner, bör uppgå i marxismen. I sin avhandlings sista stycke säger han „What this study points, towards, then, is neither convergence nor synthesis, but to transcendence of sociology, similar to Marx's transcendence of classical economics, and the development of historical materialism as the science of society" (Therborn 1974, 313). I dag är den marxistiska sociologin i sina renläriga former praktiskt taget utdöd, men den skapade betoningar och sätt att se som utan marxistiska förtecken finns i de flesta sociologiska teorier.

Ett av de nya områden, som inte skapades, men som avsevärt förstärktes under slutet av 1960-talet, var enfeministiskt orienterad kvinnossociologi. Den hade föregångare i alla nordiska länder, men från och med i stort sett 1960-talet blir analyser av kvinnors status och positioner i samhället med hjälp av sociologisk teori och metodik vanliga. Under 1980talet skedde en begreppsligt viktig förändring när man i stället för könsroller och kvinnoroller började tala om genus, på engelska gender, för att förstå de ofta subtila skillnader som finns mellan män och kvinnor i vardagslivet och reproduktionen av dem med en tydlig avspegling i kvinnornas vardagserfarenheter och omedvetna föreställningar (Hirdman 1989, 14-15), Genusforskningen har fört in den omedvetna vardagserfarenheten 
och osynliggörandet av maktförhållanden som en faktor vid utformningen av socialt liv, såsom påpekas bl a i Diana Mulinaris och Kerstin Sundells uppsats Exploring the Notion of Experience in Feminist Thought (1999, 287-297). Den feministiskt orienterade genusforskningen hör till de områden, som inriktat sig på att finna strategier och nya sätt att förhålla sig i en tid av risker och snabba nyorienteringar. Kvinnoforskningen hade redan från början protesterat mot förekomsten av fasta strukturer och inriktat sig på att finna nya strategier , såsom bl a framgår av den av Elina Haavio-Mannila tillsammans med nio andra nordiska kvinnliga sociologer skrivna boken om den ofullbordade demokratin (1985).

\section{Riktningar av både kontinuitet och förnyelse}

Alla kring slutet av 1960-talet och början av 1970-talet uppstådda och tankeomformande förhållningssätt var inte i huvudsak protester eller utmärktes av en strävan att utradera existerande teori och metodologi. Inom nordisk sociologi fanns särskilt två starka ansatser att förena kontinuitet och nyorientering. Den ena var den den nya välfärdsforskningen, som representerade en ny social inställning, men som utnyttjade vedertagna metoder. Den föddes iSverige med Sten Johanssons Om levnadsnivåundersökningen av år 1970, men spred sig till andra nordiska länder samt ledde till intensivt samarbete och till sampublikationer såsom The Scandinavian Model. Welfare States and Welfare Research (Erikson \& Hansen \& Ringen \& Uusitalo 1987). Välfärdsforskningen med noggranna mätningar av levnadsnivån har fortsatt att leva med en tyngdpunkt i Sverige, men den har utvidgats till studier av välfärdsstatens legitimitet (Svallfors 1996) och strategiska analyser av hur välfärdsstaten kommer och kan överleva
(Kuhnle 2000). Det har också funnits klart ökade tendenser till ömsesidig påverkan mellan välfärdsforskningen och studiet av social stratifiering. Tendensen syns bl a i försöket att analysera om moderna stater försöker och lyckas modifiera processer, som genererar social olikhet, vilket har skett i Robert Eriksons och John Goldthorpes $(1992,179)$ metodologiskt avancerade komparativa analys av social mobilitet $\mathrm{i}$ industriella samhällen,

Den andra stora ansatsen till en kombination av kontinuitet och förnyelse har varit den komparativa, politiska sociologins förstärkta historiska orientering (Mjöset 1998, 63-69). Den har fört med sig ökade tendenser att beakta hur politiska handlingar i nya historiska situationer vid sidan av den strukturella bakgrunden påverkar utfallet av de politiska processerna såsom i Risto Alapuros (1988) analys av nationalstaten Finlands tillblivelse. Trots påståenden om motsatsen med fortsatta antaganden om ett fruset partisysten är det uppenbart att det politiska livet i de nordiska länderna är betydligt svagare strukturellt determinerat än det var på 1950-, 1960- och 1970-talen. Vid sidan av de traditionella partierna finns det numera strukturellt icke klart identifierbara partier, både till vänster såsom de gröna och vänstersocialisterna, och till höger såsom de populistiska framstegspartierna (Jenssen 1993). Dessutom ökar ensaks- och gräsrotsrörelserna, som för att följa Peter Gundelach $(1990,413)$ uppstår, när samhällssystemet inte på ett tillfredsställande sätt kan lösa de problem och uppnå de mål, som systemet själv har definierat och formulerat. En viktig utvidgning inom den politiska sociologin uppstod mot slutet av 1970-talet när Gudmund Hernes (1978) analyserade den politiska makten i Norge med inspiration från den ekonomiska teorin om kollektiva beslut. 
Den utgjorde också första steget till uppkomsten eller pånyttfödelsen av en nordisk ekonomisk sociologi.

\section{Mot en ny och strategiskt orienterad sociologi}

Sociologin befinner sig en kritisk situation med starka krav på nyorientering. De av de ovan beskrivna riktningarna, som i dag åtnjuter popularitet och utvecklas, kan sägas vara (1) kultursociologin med en tonvikt på verklighetens sociala konstruktion, (2) den feministiska teorin, (3) välfärdsforskningen med sin strävan att finna nya socialpolitiska lösningar och (4) den historiskt orienterade komparativa sociologin. De utmärks av en minskad strukturell determinism och en betoning av mänskliga agenters förmåga att definiera problemen och att välja lösningar. Utan tvivel återspeglar sociologins utmaningar stora sociala förändringar. En av den senaste tidens centrala teman har varit globaliseringen, uppkomsten av globala styrningsmekanismer, som inte bara tenderar att minska makten hos nationalstatens demokratiskt valda organ, utan som också framkallar helt nya former av politiska protester. En annan central företeelse är informations- och computerteknologin, som grundligt förändrar arbetslivet, kommunikationsmöjligheterna och formerna för mänsklig interaktion. Det har också uppstått en intensiv diskussion om hur den ökade inriktningen på konsumtion och individens värde som konsument har lett till fragmentering, upplösning av traditionella sociala band och större valfrihet (Sulkunen m. fl. 1997).

I Therborns uppsats om sociologins förändringar och förändringstryck vid millennieskiftet ges exempel på hur många ledande sociologer nu betonar snabba förändringar och osäkerhet i stället för att presentera fasta strukturer och samhällsfunktioner med god förutsäg- barhet. Therborn $(1999,22-23)$ hänvisar bl a till Ulrich Becks tes om hur vi kommit in i riskernas samhälle, till hur Anthony Giddens i sin strukturationsteori visar att människor använder varierande strategier för att anpassa sig till samhällets klasskiktning och hur Pierre Bourdieu undersöker hur olika grupper i samhället har olika slag av kapital, sociala distinktioner och sociala definitioner för att bevara sin livsstil, habitus. En av de första, av Therborn icke nämnd teoretiker, med ett särskilt intresse för hur individer använder olika strategier, var Alain Touraine, som effektivt har betonat att den individuella aktorn, aktören är tillbaka i samhället och sociologin, „le retour de l'acteur" (1984).

Den av Therborn beskrivna kantringen mot en annorlunda sociologi har ingalunda försummats att bli observerad i de nordiska länderna. Det har betonats hur inriktningen på kultursociologi och kulturanalys är en exponent av förändringen. Risto Heiskala $(1997,329)$ skriver $\mathrm{i}$ avslutningen på sin redan nämnda bok på följande sätt: ,,analyses of the era have had the tendency to turn to culture because it has become even more problematic to talk about 'societies' as if they were entities with clearly marked boundaries". Ett av de frispråkigaste uttrycken för att vi i sociologin står inför en ny situation har vi i den av Peter Gundelach, Nils Mortensen och Jens Chr. Tonboe redigerade boken Sociologi under forandring (1990). Den utgår från och argumenterar för att gamla, traditionella skiljelinjer i samhället håller på att brytas ned och försvinna. Det inte bara de gamla skiljelinjerna i samhällsstruktur och värdemiljöer som bryts ned och tenderar att försvinna, utan också skiljelinjerna mellan nationella sociologiska miljöer, skolor, riktningar och metoduppfattningar. 
Den nya situationen och sociologins nya inriktning syns redan i många specialundersökningar. Peter Gundelachs (1984) studier av gräsrotsrörelserna hör till dem, liksom också många studier av de nya dragen i ungdomskulturen (Gudmundsson (1898, 57-61). När Jukka Gronow undersöker smaken som socialt fenomen, beskriver han inte hur den ter sig i olika klasser och grupper, utan han påvisar smakens centrala roll i dagens samhälle. Smaken skapar „communities of taste", som befinner sig "in a constant state of being born and dying out" (Gronow 1997, 171).

Signifikant för den nya situationen med inriktning på strategi och osäkerhet om vart samhället är på väg är att den genre, som man kallar samtidsdiagnos, visar ett markant uppsving. Den är ingalunda förbehållen enbart sociologer. Ett av de mest uppmärksammade bidragen från de senaste årtiondena var kemins mobelpristagare Ilya Prigogines beskrivning om hur samhället börjat likna gasmassor som utmärks av bifurkation, olika vägar att välja mellan (Prigogine \& Stengers 1984). Sociologerna har ingalunda varit passiva. Det är värt att notera att ett av år 2000s nummer av både Norges och Finlands sociologtidskrifter innehåller av varandra oberoende artiklar om samtidsdiagnosens innehåll och uppgifter. På finska skriver Arto Noro (2000, Nr 4) och på norska Lars Mjöset (2000, 53-75). Hos Noro finns den intressanta, visserligen i en försiktig form framförda tankegången att epoken och nuläget har tagit det nationella samhällets plats i sociologisk analys.

\section{Litteratur}

Alasuutari, Pertti, 1995: Researching Culture. Qualitative Method and Cultural Studies. London: Sage Publications.

Alapuro, Risto, 1998: State and Revolution in Finland. Berkeley/Los Ange-
les/London: University of California Press.

Allardt, Erik, 1970: „Types of Protests and Alienation". I Erik Allardt \& Rokkan, Stein (eds), Mass Politics. Studies in Political Sociology. New York: The Free Press, s. 45-63.

Asplund, Johan, 1968: „Om värdeneutralitet i vetenskapen“. Sociologisk forskning V: 245-263.

Aubert, Vilhelm, 1965: The Hidden Society, Totowa: Bedminster Press. Och 1969: Det skjulte samfunn. Oslo: Universitetsforlaget.

Boalt, Gunnar, 1959: „Den enskilda individen som individ, som medlem i massa och grupper". Människan och arbetet I-II. Stockholm: Strömbergs, s 33-122.

Due, Jesper \& Madsen, Jörgen Steen, 1983: Slip sociologien lös. - en invitation till 80'ernes sociologi, Köbenhavn: Hans Reitzel. Durkheim, Émile, 1895: „L'origine du mariage dans l'espèce humaine". Revue Philosophique XL: 602-623.

Durkheim, Émile, 1907: „Westermarck, Edward: The Origin and Development of the Moral Ideas", Année Sociologique X: 383-395.

Erikson, Robert \& Hansen, Erik Jörgen \& Ringen, Stein \& Uusitalo, Hannu (eds), 1987: The Scandinavian Model. Welfare States and Welfare Research. Armonk, New York: M.E. Sharpe, Inc. Erikson, Robert \&

Goldthorpe, John H., 1992: The Constant Flux. A Study of Class Mobility in Industrial Society, Oxford:Clarendon Press.

Geiger, Theodor, 1939: Sociologi. Grundrids og hovedproblemer. Köbenhavn: Nyt Nordisk Forlag, Arnold Busck.

Gronow, Jukka, 1997: The Sociology of Taste. London: Routledge.

Gudmundsson, Gestur, 1998: „Youth and Sociology: The Nordic Contribution in a Global Perspective“. I Bertils- 
son, Margareta \& Therborn,Göran (eds), From a Doll's House to the Welfare State: Reflections on Nordic Sociology. Pre-Congress Volumes, International Sociological Association, s. 57-61.

Gundelach, Peter, 1984: „Social Transformation and New Forms of Voluntary Associations".Social Science Information 23: 1049- 1081.

Gundelach, Peter \& Mortensen, Nils \& Tonboe, Jens Chr.(red.), 1990: Sociologi under forandring. Copenhagen: Gyldendal.

Haavio-Mannila, Elina et al,, 1985: Unfinished Democracy - Women in Nordic Politics. Oxford: Pergamon Press.

Hedström, Peter \& Swedberg, Richard (eds), 1998: Social Mechanisms. An Analytical Approach to Social Theory, Cambridge: Cambridge University Press.

Heiskala, Risto, 1997: Society as Semiosis. Neostructuralist Theory of Culture and Society. Helsinki: Department of Sociology, University of Helsinki.

Hernes, Gudmund (red), 1978: Forhandlingsökonomi og blandingsadministrasjon, Bergen; Universitetsforlaget.

Hirdman, Yvonne, 1989: Att lägga livet till rätta. Studier i svensk folkhemspolitik. Stockholm: Carlssons.

Jenssen, Anders Todal, 1993: Verdivalg. Ny massepolitikk i Norge, Oslo: Ad Notam Gyldendal.

Johansson, Sten, 1970: Om levnadsnivåundersökningen, Stockholm: allmänna förlaget.

Järvinen, Margaretha \& Bertilsson, Margareta (red.), 1998: Socialkonstruktivisme, Bidrag til en kritisk diskussion. Köbenhavn: Hans Reitzel.

Jörgensen, Jörgen, 1941: Psykologi paa biologisk grundlag. Köbenhavn: Munksgaard.

Kuhnle, Stein (ed), 2000: Survival of the European Welfare State, London and New York: Routledge. Menneske og miljö. Menneskekundskab og menneskebehandling. Människa och miljö, Band 1-3, 1946-48: tidskrift utgiven av Nyt Nordisk Forlag (Kobenhavn), C.W.K. Gleerups Förlag (Lund), Natur och Kultur (Stockholm och Akademiska Bokhandeln (Helsingfors).

Mjöset, Lars, 1998: „Nordic Comparative Macrosociology", I Bertilsson, Margareta \& Therborn, Göran (eds), From a Doll's House to the Welfare State: Reflections on Nordic Sociology.

Pre-Congress Volumes, International Sociological Association, s.63-69.

Mjöset, Lars, 2000: „Samtidsfortolkning i norsk sosiologi“. Sosiologi i dag 30: 53-75.

Mulinari, Diana \& Sandell, Kerstin, 1999: „Exploring the Notion of Experience in Feminist Thought". Acta Sociologica 42: 287-297.

Noro, Arto, 2000: „Aikalaisdiagnoosi sosiologisen teorian kolmantena lajityyppinä"(Samtidsdiagnosen som den sociologiska teorins tredje artform): Sosiologia 37: Nr. 4.

Prigogine, Ilya \& Stengers, Isabelle, 1984: Order out of Chaos. Man's New Dialogue with Nature. Toronto: Bantam Books.

Rokkan, Stein, 1970: Citizens, Elections, Parties. Approaches to the Comparative Study of the Processes of Development. Oslo: Universitetsforlaget.

Schanz, Hans-Jörgen, 1974: Til rekonstruktionen af kritikken af den politiske ökonomis omfangslogiske status. Århus.

Segerstedt, Torgny, Ordens makt, 1944, ny upplaga 1968: Ordens makt. En inledning $i$ språkets sociologi. Uppsala: Argos.

Segerstedt, Torgny, 1955: „The Uppsala School of Sociology". Acta Sociologica 1: 85-119.

Skjervheim, Hans, 1974: Objektivismen og studiet av mennesket, Oslo.

Sulkunen, Pekka et. al, (eds), 1997: Constructing the New Consumer Society. Ho- 
undmills, Great Britain: MacMillan Press.

Svalastoga, Kaare, 1965: Social Differentiation. New York: McKay.

Svallfors, Stefan, 1996: Välfärdstatens moraliska ekonomi. Välfärdsopinionen i 90-talets Sverige. Umeå: Boréa.

Therborn, Göran, 1974: Science, Class and Society. On the Formation of Sociology and Historical Materialism. Göteborg; RevoPress.

Therborn, Göran, 1999: „Sociologiens förste århundrede - og det neste“" Dansk Sosiologi 10: 19-40.

Touraine, Alain, 1984: Le retour de l'acteur. Paris:Fayard.

Uddenberg, Nils, 1998: Arvsdygden. Biologisk utveckling och mänsklig gemenskap. Stockholm: Natur och Kultur.
Westermarck, Edward, 1891: The History of Human Marriage. London: MacMillan.

Westermarck, Edward, 1906-08: The Origin and Development of the Moral Ideas I-II. London: Macmillan. von Wright, Georg Henrik, 1971: Explanation and Understanding. Ithaca: Cornell University Press.

Wrong, Dennis H., 1961: „The Oversocialized Concept of Man inModern Sociology". American Sociological Review 26: 183-193.

Zetterberg, Hans L., 1957: „Compliant Actions". Acta Sociologica 2: 179-202.

Österberg, Dag, 1988; Metasociology. An Inquiry into the Origins and Validity of Social Thought. Oslo: Universitetsforlaget. 